\title{
Retrospective Analysis of the Efficacy of Gemcitabine for Previously Treated AIDS-Associated Kaposi's Sarcoma in Western Kenya
}

\author{
R. Matthew Strother ${ }^{a}$ Kelly M. Gregory ${ }^{b}$ Sonak D. Pastakiab ${ }^{b a m e l a ~ W e r e ~}{ }^{d, f}$ \\ Constance Tenge $^{e, f}$ Naftali Busakhala ${ }^{e}$ Beatrice Jakait ${ }^{d, f}$ Ellen M. Schellhase ${ }^{b}$ \\ Alan G. Rosmarin ${ }^{c}$ Patrick J. Loehrer ${ }^{\text {a }}$ \\ ${ }^{a}$ Indiana University School of Medicine, Indianapolis, Ind., ${ }^{b}$ Purdue University School of Pharmacy and \\ Pharmaceutical Sciences, West Lafayette, Ind., and ' University of Massachusetts Medical School, \\ Worcester, Mass., USA; ${ }^{\mathrm{d}}$ Moi Teaching and Referral Hospital, and ${ }^{\mathrm{e}}$ Moi University School of Medicine, \\ Eldoret, Kenya; fUSAID-AMPATH Partnership
}

\section{Key Words}

Gemcitabine · Sarcoma · Second-line chemotherapy •

Tolerability · Treatment outcome

\begin{abstract}
Objectives: Evaluation of outcomes in the use of singleagent gemcitabine for the treatment of AIDS-associated Kaposi's sarcoma (KS) in a western Kenyan cancer treatment program. Methods: Retrospective chart review of all patients with KS treated with single agent gemcitabine following failure of first-line Adriamycin, bleomycin, and vincristine (ABV). Baseline demographics were collected, and clinicians' assessments of response were utilized to fill out objective criteria for both response as well as symptom benefit assessment. Results: Twenty-three patients with KS who had previously failed first-line therapy with $A B V$ were evaluated. Following treatment, 22 of the 23 patients responded positively to treatment with stable disease or better. Of the 18 patients who had completed therapy, with a median follow-up of 5 months, 12 patients had no documented pro-
\end{abstract}

gression. Conclusions: Treatment options in the resourceconstrained setting are limited, both by financial constraints as well as the need to avoid myelotoxicity, which is associated with high morbidity in this treatment setting. This work shows that gemcitabine has promising activity in KS, with both objective responses and clinical benefit observed in this care setting. Gemcitabine as a single agent merits further investigation for AIDS-associated KS.

Copyright $\odot 2010$ S. Karger AG, Basel

\section{Background}

Kaposi's sarcoma (KS), originally described in 1872 as an indolent pigmented mucocutaneous malignancy evolving over $10-15$ years, was subsequently described as an malignancy endemic to Africa, with several variant

K.M.G. and R.M.S. contributed equally to the creation of this document.

\section{KARGER}

Fax +4161306 1234

E-Mail karger@karger.ch

www.karger.com
(C) 2010 S. Karger AG, Basel

0030-2414/10/0781-0005\$26.00/0

Accessible online at:

www.karger.com/ocl
R. Matthew Strother

Indiana University School of Medicine

IU Simon Cancer Center, 535 Barnhill Drive

Indianapolis, IN 46202 (USA)

Tel. +1 317278 5000, E-Mail rstrothe@gmail.com 
presentations and clinical courses [1]. Heralding the start of the AIDS era, KS was described in young homosexual men, and was later linked to immunodeficiency from HIV [2]. The prevalence of HIV in Africa, along with the prevalence of human herpesvirus 8 (the causative agent of epidemic KS [3]), has led to a marked prevalence of KS in Sub-Saharan Africa, where it is the most common cancer affecting males (12.9\% of all diagnosed cancer) and third most common cancer of females $(5.1 \%$ of malignancy) [4]. In Uganda, neighboring Kenya to the west, KS represents 50\% of tumors seen in HIV-positive men [5]. Untreated, either with combination antiretroviral therapy (cART) or chemotherapeutics, the prognosis of this malignancy can be less than 6 months [6].

While implementation of anti-retroviral therapy has markedly reduced the incidence of AIDS-associated KS in Europe [7], late-presentation disease combined with unavailability of cART means that systemic chemotherapy with palliative intent has become a mainstay of KS treatment in Sub-Saharan Africa [8-10]. A wide variety of systemic chemotherapeutic agents have been efficacious in KS, both as single agents and as combination chemotherapy, including vincristine $[11,12]$, bleomycin [13-15], anthracyclines [15-17], interferon [18], paclitaxel $[19,20]$, and etoposide [21]. In resource-replete settings, liposome-encapsulated doxorubicin is the standard of care, with response rates up to $80 \%$ and durable remissions of disease lasting for years are common $[22,23]$. However, in resource-limited settings where cost of therapy can become paramount combined with relative lack of trials, a gold-standard for therapy remains unclear [24]. The combination regimen of Adriamycin, bleomycin, and vincristine (ABV) is common, with an approximately $25 \%$ response rate and a cost making it feasible to pursue $[15,17,25]$.

Western Kenya is the site of an innovative comprehensive HIV/AIDS care program, the Academic Model for Providing Access to Healthcare (AMPATH) - United States Agency for International Development (USAID) Partnership. In conjunction with the Moi Teaching and Referral Hospital and Moi University, the AMPATHUSAID Partnership has developed cancer services over the last 8 years to address the burden of malignancy found in the HIV/AIDS population [26, 27]. Oncology services, limited to chemotherapy and palliative care, are offered at AMPATH's central location in Eldoret and at 5 satellite clinics throughout western Kenya. Satellite clinics see patients on a 4 -week rotation, allowing all patients enrolled in cancer services to be seen monthly at minimum. This has important implications for feasible che- motherapy schedules in this practice environment. Patients presenting with AIDS-related KS, with no improvement in spite of initiation of CART, are offered ABV as first-line treatment. However, with a $75 \%$ failure rate, other options for therapy need to be explored. Based on a case series in classical KS, and a kind donation from Eli Lilly and Co. to the USAID-AMPATH Partnership, gemcitabine was explored as second-line therapy in patients who failed ABV [28].

Gemcitabine (2',2'-difluoro-2'-deoxycytidine) is an S-phase nucleoside anti-metabolite that has demonstrated activity in a variety of solid tumors, including sarcomas. The most common dose and schedule of this agent is $1,000 \mathrm{mg} / \mathrm{m}^{2}$, given on days 1,8 , and 15 of a 21 day cycle for pancreatic cancer, but schedules for other indications vary (i.e. monthly for refractory non-Hodgkin's lymphoma). The toxicity profile of gemcitabine is acceptable in resource-limited settings, with a dose-limiting toxicity of thrombocytopenia - avoiding the excessive risks of neutropenia in resource-limited settings (associated with higher morbidity in the developing world) [5]. Under this program, 32 patients were treated with gemcitabine from August 2006 to October 2007. Patients were treated with both single-agent gemcitabine and gemcitabine in combination with other agents (most frequently bleomycin, vincristine, or cyclophosphamide). Based on clinician anecdote, it was felt that there were significant responses to gemcitabine amongst patients who had failed prior lines of chemotherapy. To explore this anecdotal evidence, a retrospective chart review was conducted for 23 consecutive patients who received gemcitabine monotherapy for mucocutaneous AIDS-related KS and had previously failed ABV as firstline therapy.

\section{Methods}

Of all the patients treated with gemcitabine from August 2006 to October 2007 , only patients who received single-agent gemcitabine following documented failure on ABV were selected for further analysis. Twenty-three patients with documented progression of KS lesions while on ABV and cART were included. The following data were collected by paper chart review: patient demographics, opportunistic infections, date of HIV diagnosis, start date of cART, cART regimen, duration of cART prior to gemcitabine, CD4 counts, date of KS diagnosis, lesion description, Karnofsky Performance Status score, pain and analgesic usage (derived from a separate pharmacy database), assessment of chemotherapy dose and cycle, as well as deviations from routine therapy, and incidence and description of adverse events. Using records from initial oncology clinic evaluations and other perti- 
nent AMPATH-USAID records, a determination of the probable AIDS Clinical Trials Group oncology staging of AIDS-related KS on presentation (prior to any therapy) was completed [29]. The presence of KS in the gastrointestinal tract and other non-nodal viscera was not included in the definition of disseminated disease as the diagnostic tools necessary to confirm the presence of KS in these areas were not available. Additionally, due to lack of local resources, the majority of patients in this setting are treated based on clinical diagnosis; therefore, pathology was not available for all patients treated during this period.

Responses were evaluated at 4-week intervals (all patients are scheduled at a minimum of 4 -week intervals in this practice setting) and at the last follow-up visit recorded on the chart. Assessment of KS lesion response was limited to mucocutaneous lesions only, again due to the lack of additional diagnostic equipment. For the purpose of this analysis, and based on the work of Okuno et al. [28], the following definitions of response were created: patients free of all lesions for $\geq 4$ weeks were considered to have a complete response, partial response was defined as a $>50 \%$ reduction in lesions for $\geq 4$ weeks, no significant change in size of or appearance of new lesions was considered stable disease, and progressive disease was defined as an increase in the size of existing lesions or appearance of new lesions.

Additional endpoints assessed include progression-free survival and clinical benefit response. Progression-free survival was assessed in patients who completed all planned gemcitabine prior to completion of this chart review. Clinical benefit response was based on the methods utilized in 2 trials evaluating the use of gemcitabine in patients with locally advanced or metastatic pancreatic cancer [30-32]. An adaptation of this validated composite measure, which is based on analgesic consumption, pain intensity, performance status, and weight change, was created to allow for an objective interpretation of subjective chart notes. Because of intermittent sparse documentation in the clinical charts, the following definition of clinical benefit was created prior to initiation of the chart review. Either of the following criteria defined a clinical benefit for the purposes of this analysis: (1) the patient achieved a $\geq 50 \%$ reduction in pain intensity or analgesic consumption, or a 20 -point or greater improvement in Karnofsky Performance Status for a period of at least 4 consecutive weeks, without showing any sustained worsening in any of the other parameters; (2) the patient was stable on all of the aforementioned parameters, and showed a sustained weight gain of at least $7 \%$ maintained for $\geq 4$ weeks. Absence of clinical benefit was defined as 4 consecutive weeks with either: (1) an increase in pain intensity or analgesic consumption; (2) a 20-point decrease in performance status occurring during the first 12 weeks of therapy.

To assess for toxicity, charts were examined for evidence of the following: anemia, leukopenia, neutropenia, thrombocytopenia, edema, renal dysfunction, hepatic dysfunction, fatigue, fever, weight loss, pneumonitis/pulmonary infiltrates, constipation, nausea, emesis, infection, pain, and dyspnea. Toxicities were graded per the Cancer Therapy Evaluation Program's Common Terminology Criteria for Adverse Events, version 3.0 [33]. As laboratory testing was limited to complete blood counts for the majority of patients, several toxicities could not be assessed (e.g. electrolyte imbalances, renal toxicity, and hepatic toxicity).

Efficacy of Gemcitabine for Kaposi's

Sarcoma

\section{Results}

\section{Patient Characteristics}

Twenty-three charts were reviewed, the results of which are summarized in table 1 . There were 19 males (82.6\%) and 4 females (17.4\%), with a median age of 37 years (range: 20-57 years). Patients were on cART for a median of 12 months (range: 4-41 months) before starting gemcitabine. According to the AIDS Clinical Trials Group staging, all patients were poor-risk, based on tumor extent, CD 4 cell count $<200$ cells $/ \mathrm{mm}^{3}$, concurrent systemic illness or Karnofsky Performance Status score $<70 \%$.

\section{Chemotherapy Regimens}

As noted, gemcitabine was delivered in a variety of combinations. This analysis focused on single-agent administration. However, even in this limited utilization of the drug, there were practitioner-level differences in the dosing and scheduling of administration. Two regimens were used, a fixed-dose regimen, and a BSA-adjusted dose. Eighty-three percent (19/23) of patients received a fixed dose of 1,000 $\mathrm{mg}, 13 \%$ (3/23) received $1,000 \mathrm{mg} / \mathrm{m}^{2}$, and $4 \%(1 / 23)$ received both dosing regimens.

It was intended that all patients receive gemcitabine on a 14-day cycle. Most patients achieved this, with a median time between doses of 17 days (range: 13-31). The reasons given in the medical record for all missed or delayed cycles are presented in table 2 . The number of patients who missed at least 1 dose was 13 (57\%). There was no commonly accepted maximum number of cycles to be delivered in this setting. A median of 7 cycles (range: 3-15 cycles) was delivered to these patients.

\section{Tumor Response Data}

The response of KS to single-agent gemcitabine is presented in table 3 . At the time of completion of this retrospective chart review, with a median follow-up of 5.1 months (range: $2-10$ months), 2 of the 23 patients were still receiving gemcitabine therapy, 3 patients were lost to follow-up, and 18 patients were no longer receiving gemcitabine. Of the 18 patients who completed treatment, 12 had no documentation of progression, with a median follow-up of 5 months (range: 2.5-7 months), 5 had progressive disease, with a mean progression-free survival of 1.7 months (range: $0-3$ months), and 1 died within 2 months of completion of gemcitabine, with no progression of KS, but death secondary to hepatocellular carcinoma. 
Table 1. Baseline characteristics $(n=23)$

\begin{tabular}{|c|c|c|}
\hline & Median and range & $\%$ \\
\hline Age, years & $37(20-57)$ & - \\
\hline \multicolumn{3}{|l|}{ Gender } \\
\hline Male & 19 & 83 \\
\hline Female & 4 & 17 \\
\hline $\mathrm{CD} 4$ count prior to ABV-based therapy, cells $/ \mathrm{mm}^{3}$ & $145(12-536)$ & - \\
\hline CD4 count prior to gemcitabine, cells $/ \mathrm{mm}^{3}$ & $168(39-631)$ & - \\
\hline Time on cART, months & $12(4-41)$ & - \\
\hline \multicolumn{3}{|l|}{ Tumor classification $(\mathrm{T})$ : } \\
\hline $\begin{array}{l}\text { Good risk (confined to skin and/or lymph nodes } \\
\text { and/or minimal oral disease) }\end{array}$ & 0 & 0 \\
\hline Poor risk & 23 & 100 \\
\hline Tumor-associated edema or ulceration & 22 & 95.7 \\
\hline Extensive oral KS & 8 & 34.8 \\
\hline \multicolumn{3}{|l|}{ Tumor classification: immune system (I) } \\
\hline Good risk (CD4 cells $\geq 200$ cells $\left./ \mathrm{mm}^{3}\right)$ & 5 & 21.8 \\
\hline Poor risk (CD4 cells $<200$ cells $/ \mathrm{mm}^{3}$ ) & 18 & 78.3 \\
\hline \multicolumn{3}{|l|}{ Tumor classification: systemic illness (S) } \\
\hline Good risk & 3 & 13 \\
\hline Poor risk & 20 & 87 \\
\hline \multicolumn{3}{|l|}{ Karnofsky performance status, $\%$} \\
\hline Mean & - & 64 \\
\hline Range & - & $50-80$ \\
\hline $80 \%$ & 2 & 9 \\
\hline $70 \%$ & 9 & 39 \\
\hline $60 \%$ & 9 & 39 \\
\hline $50 \%$ & 3 & 13 \\
\hline
\end{tabular}

Table 2. Causes of missed/delayed gemcitabine doses $(n=23)$

\begin{tabular}{lc}
\hline & Incidence \\
\hline Anemia & 1 \\
Complete blood cell count not performed & 1 \\
Neutropenia & 2 \\
No transportation & 13 \\
Too ill & 4 \\
Unspecified & 6 \\
\hline Total missed/delayed doses & 27 \\
\hline
\end{tabular}

\section{Clinical Benefit Response}

Fifteen of the 23 patients (65\%) showed evidence in their records of a clinical benefit response to single-agent gemcitabine. Details of this assessment are presented in table 4.

\section{Toxicity Data}

No patients died as a result of receiving gemcitabine. Table 5 summarizes the observed toxicities.
Table 3. Response results $(n=23)$

\begin{tabular}{lrr}
\hline & $\mathrm{n}$ & $\%$ \\
\hline Complete response & 3 & 13 \\
Partial response & 8 & 35 \\
Stable disease & 11 & 48 \\
Progressive disease & 1 & 4 \\
\hline
\end{tabular}

\section{Discussion}

Cancer is a global health problem - in the next 10-15 years the incidence of new cancers will rise to 15 million cases annually, of which $75 \%$ will be in developing countries [34]. In 2002 in Sub-Saharan Africa alone, there were more than 500,000 cancer deaths [35]. Access to cancer care is limited in Africa - health care providers are infrequently trained in oncology, chemotherapy is extremely limited, and less than half of the countries in Africa have radiation therapy units [36]. Accelerating the 
Table 4. Clinical benefit response $(n=23)$

\begin{tabular}{lrr}
\hline & $\mathrm{n}$ & $\%$ \\
\hline$\geq 50 \%$ reduction in pain intensity & 12 & 52 \\
$\geq 50 \%$ reduction in analgesic consumption & 9 & 40 \\
20 point improvement in Karnofsky Performance Status for & 8 & 35 \\
$\quad \geq 4$ consecutive weeks & 2 & 9 \\
Sustained weight gain of $\geq 7 \%$ maintained for $\geq 4$ consecutive weeks & 15 & 65 \\
\hline Clinical benefit response achieved & 15 \\
\hline
\end{tabular}

Table 5. Incidence of toxicities $(n=23)$

\begin{tabular}{lcc}
\hline & \multicolumn{2}{l}{ Grade } \\
\cline { 2 - 3 } & 3 & 4 \\
\hline Anemia & $1^{\mathrm{a}}$ & - \\
Dyspnea & 1 & - \\
Fatigue & 3 & - \\
Infection & 1 & - \\
Leukopenia & 1 & 3 \\
Neutropenia & $2^{\mathrm{b}}$ & - \\
Pain & 3 & 1 \\
Pulmonary infiltrates & 1 & - \\
\hline Total & 13 & 4 \\
\hline
\end{tabular}

${ }^{a}$ Hemoglobin: $6.7 \mathrm{~g} / \mathrm{dl}$.

${ }^{\mathrm{b}}$ Absolute neutrophil counts: 1,075 and 1,120 cells $/ \mathrm{mm}^{3}$.

growth of cancer in developing countries has been the HIV/AIDS pandemic - the epicenter of which is Sub-Saharan Africa, accounting for $67 \%$ of the world's HIVpositive population - 2 million in Kenya alone [37, 38]. Improving availability of adequate cART has been limited, with present estimates stating that between 31 and $48 \%$ of those who need cART are receiving it [37]. With this degree of disease burden, care for HIV-associated malignancy, both AIDS-defining (cervical cancer, KS, and non-Hodgkin's lymphoma) and AIDS-associated, is rapidly evolving into a second wave of HIV-associated morbidity and mortality, one not entirely alleviated by initiation of cART $[5,39]$. It is critical to develop treatment options for cancer appropriate to the diseases seen as well as the context of care in resource-limited settings.

Combination chemotherapy with ABV has been shown to be both cost-effective and efficacious in resource-limited settings [25]. However, with only a $25 \%$ response rate in KS, there is a clear need to find alternative regimens. This retrospective analysis attempted to define the efficacy of gemcitabine for this disease, in spite of administration of the chemotherapy in a non-research environment. Gemcitabine was made available to Kenyan clinicians in this setting through a donation from Eli Lilly and Co., as part of their ongoing philanthropic contributions to the AMPATH-USAID partnership. Local clinicians utilized this drug for KS (based on case reports in the literature) as the next line in palliative treatment of HIV-positive patients with KS, guided by necessity because of an absence of other treatment options for these patients. Data were collected as part of routine clinical treatment, not in the scope of a clinical trial. Utilizing data from routine clinical practice for the analysis presents several difficulties in the interpretation of results; however, given the clinicians' anecdotal sense of success, making an effort to compile these data and present the results of this analysis to the oncology community at large felt justified.

Specific concerns with these data include a lack of preestablished guidelines for judging response (i.e. RECIST [40]), lack of uniformity in dose and schedule, and inadequate follow-up for toxicity. Many of these issues are reflective of the practice environment of western Kenya, where oncology services have only recently been introduced and many resources are not routinely available (i.e. imaging, 'routine' blood work). Additionally, there were a number of missed or delay doses, most frequently due to lack of transportation (13 missed doses) and illness (4 missed doses), again reflective of the resource-limited care environment. However, in spite of these limitations, this analysis offers evidence of reasonable efficacy of gemcitabine for KS - certainly sufficient evidence to merit follow-up with a well-controlled clinical trial, which we are at present preparing to undertake. Further, from the limited evidence available within this analysis, it appears that efficacy is possible without excess toxicity - a critical concern in a practice environment in which excess toxicity does not translate simply to morbidity as it does in resource-replete care settings, but to mortality. It should 
be noted that there were difficulties in performing an adequate assessment of toxicity that may lead to bias in this interpretation - for instance, the incidence of myelosuppression may be under accounted for as complete blood counts were only obtained prior to $48 \%$ of doses, again due to lack of available resources or technology. However, in spite of these methodological concerns, the available evidence presented in this analysis certainly justifies pursuing a prospective study examining gemcitabine for first-line therapy of AIDS-related KS.

Despite modest dosages, gemcitabine appears to have substantial activity in previously treated AIDS-associated KS. Confirmation of activity in mucocutaneous and visceral KS is necessary. While barriers to treatment exist in Kenya, it appears both feasible to successfully administer gemcitabine in this resource-constrained practice environment, as well as effective in therapy for AIDSassociated KS. A phase II clinical trial is currently being designed by oncology physicians from the Indiana University School of Medicine and Moi University Teaching and Referral Hospital.

\section{Acknowledgments}

This research was supported in part by a grant to the USAIDAMPATH Partnership from the United States Agency for International Development as part of the President's Emergency Plan for AIDS Relief and the Levison Family Foundation. Gemcitabine was provided by a donation from Eli Lilly and Co. to the USAID-AMPATH Partnership, and P.J.L. receives grant funding from Eli Lilly and Co.

\section{References}

1 Taylor JF, Templeton AC, Vogel CL, Ziegler JL, Kyalwazi SK: Kaposi's sarcoma in Uganda: a clinico-pathological study. Int J Cancer 1971;8:122-135.

-2 Hymes KB, Cheung T, Greene JB, Prose NS, Marcus A, Ballard H, William DC, Laubenstein LJ: Kaposi's sarcoma in homosexual men - a report of eight cases. Lancet 1981;2: 598-600.

-3 Chang Y, Cesarman E, Pessin MS, Lee F, Culpepper J, Knowles DM, Moore PS: Identification of herpesvirus-like DNA sequences in AIDS-associated Kaposi's sarcoma. Science 1994;266:1865-1869.

4 Parkin DM, Sitas F, Chirenje M, Stein L, Abratt R, Wabinga H: Part I: cancer in indigenous Africans - burden, distribution, and trends. Lancet Oncol 2008;9:683-692.

5 Orem J, Otieno MW, Remick SC: Challenges and opportunities for treatment and research of AIDS-related malignancies in Africa. Curr Opin Oncol 2006;18:479-486.

-6 Mwanda OW, Fu P, Collea R, Whalen C, Remick SC: Kaposi's sarcoma in patients with and without human immunodeficiency virus infection, in a tertiary referral centre in Kenya. Ann Trop Med Parasitol 2005;99:8191.

7 Mocroft A, Kirk O, Clumeck N, Gargalianos-Kakolyris $\mathrm{P}$, Trocha $\mathrm{H}$, Chentsova $\mathrm{N}$, Antunes F, Stellbrink HJ, Phillips AN, Lundgren JD: The changing pattern of Kaposi sarcoma in patients with HIV, 1994-2003: the EuroSIDA Study. Cancer 2004;100:26442654.

8 Von Roenn JH: Clinical presentations and standard therapy of AIDS-associated Kaposi's sarcoma. Hematol Oncol Clin North Am 2003; 17:747-762.
9 Hengge UR, Ruzicka T, Tyring SK, Stuschke M, Roggendorf M, Schwartz RA, Seeber S: Update on Kaposi's sarcoma and other HHV8 associated diseases. 1. Epidemiology, environmental predispositions, clinical manifestations, and therapy. Lancet Infect Dis 2002;2:281-292.

$\checkmark 10$ Levine AM, Tulpule A: Clinical aspects and management of AIDS-related Kaposi's sarcoma. Eur J Cancer 2001;37:1288-1295.

11 Lingenfelser T, Daiss W, Overkamp D, Weber P: Successful monochemotherapy of extensive gastrointestinal Kaposi's sarcoma with bowel obstruction in acquired immunodeficiency syndrome. Z Gastroenterol 1994;32:688-690.

12 Akay S, Karasu Z, Akyildiz M, Tokat Y, Goker E: Successful treatment of liver transplant-associated Kaposi's sarcoma with long-term vincristine. Transplant Proc 2005; 37:2188-2189.

13 Lipman MC, Swaden LS, Sabin CA, Collis C, Johnson MA: Kaposi's sarcoma in HIV infection treated with vincristine and bleomycin. AIDS 1993;7:592-593.

14 Paparizos VA, Kyriakis KP, Mileounis KA, Pfandl-Polydorou D, Stavrianeas NG, Vareltzidis AG, Stratigos JD: Experience with Adriamycin, bleomycin, vincristine (ABV) palliative chemotherapy in advanced AIDSrelated Kaposi's sarcoma. J Chemother 1996; 8:403-406.

15 Northfelt DW, Dezube BJ, Thommes JA, Miller BJ, Fischl MA, Friedman-Kien A, Kaplan LD, Du Mond C, Mamelok RD, Henry $\mathrm{DH}$ : Pegylated-liposomal doxorubicin versus doxorubicin, bleomycin, and vincristine in the treatment of AIDS-related Kaposi's sarcoma: results of a randomized phase III clinical trial. J Clin Oncol 1998; 16:24452451.
16 Northfelt DW, Dezube BJ, Thommes JA, Levine R, Von Roenn JH, Dosik GM, Rios A, Krown SE, DuMond C, Mamelok RD: Efficacy of pegylated-liposomal doxorubicin in the treatment of AIDS-related Kaposi's sarcoma after failure of standard chemotherapy. J Clin Oncol 1997;15:653-659.

17 Gill PS, Wernz J, Scadden DT, Cohen P, Mukwaya GM, von Roenn JH, Jacobs M, Kempin S, Silverberg I, Gonzales G, Rarick MU, Myers AM, Shepherd F, Sawka C, Pike MC, Ross ME: Randomized phase III trial of liposomal daunorubicin versus doxorubicin, bleomycin, and vincristine in AIDS-related Kaposi's sarcoma. J Clin Oncol 1996;14: 2353-2364.

18 Shepherd FA, Evans WK, Garvey B, Read SE, Klein M, Fanning MM, Coates R: Combination chemotherapy and alpha-interferon in the treatment of Kaposi's sarcoma associated with acquired immune deficiency syndrome. CMAJ 1988;139:635-639.

19 Welles L, Saville MW, Lietzau J, Pluda JM, Wyvill KM, Feuerstein I, Figg WD, Lush R, Odom J, Wilson WH, Fajardo MT, Humphrey RW, Feigal E, Tuck D, Steinberg SM, Broder S, Yarchoan R: Phase II trial with dose titration of paclitaxel for the therapy of human immunodeficiency virus-associated Kaposi's sarcoma. J Clin Oncol 1998;16: 1112-1121.

-20 Saville MW, Lietzau J, Pluda JM, Feuerstein I, Odom J, Wilson WH, Humphrey RW, Feigal E, Steinberg SM, Broder S, et al: Treatment of HIV-associated Kaposi's sarcoma with paclitaxel. Lancet 1995;346:26-28. 
-21 Evans SR, Krown SE, Testa MA, Cooley TP, Von Roenn JH: Phase II evaluation of lowdose oral etoposide for the treatment of relapsed or progressive AIDS-related Kaposi's sarcoma: an AIDS Clinical Trials Group clinical study. J Clin Oncol 2002;20:32363241.

-22 Lichterfeld M, Qurishi N, Hoffmann C, Hochdorfer B, Brockmeyer NH, Arasteh K, Mauss S, Rockstroh JK: Treatment of HIV-1associated Kaposi's sarcoma with pegylated liposomal doxorubicin and HAART simultaneously induces effective tumor remission and CD4+ T cell recovery. Infection 2005;33: 140-147.

-23 Martin-Carbonero L, Palacios R, Valencia E, Saballs P, Sirera G, Santos I, Baldobi F, Alegre M, Goyenechea A, Pedreira J, Gonzalez del Castillo J, Martinez-Lacasa J, Ocampo A, Alsina M, Santos J, Podzamczer D, GonzalezLahoz J: Long-term prognosis of HIV-infected patients with Kaposi sarcoma treated with pegylated liposomal doxorubicin. Clin Infect Dis 2008;47:410-417.

24 Dedicoat M, Newton R: Treatment of Kaposi's sarcoma in resource-poor settings. Trop Doct 2005;35:60.

25 Vanni T, Fonseca BA, Polanczyk CA: Costeffectiveness analysis comparing chemotherapy regimens in the treatment of AIDSrelated Kaposi's sarcoma in Brazil. HIV Clin Trials 2006;7:194-202.

26 Einterz RM, Kelley CR, Mamlin JJ, Van Reken DE: Partnerships in international health. The Indiana University-Moi University experience. Infect Dis Clin North Am 1995;9: $453-455$.
27 Einterz RM, Kimaiyo S, Mengech HNK, Khwa-Otsyula BO, Esamai F, Quigley F, Mamlin JJ: Responding to the HIV pandemic: the power of an academic medical partnership. Acad Med 2007;82:812-818.

28 Okuno S, Edmonson J, Mahoney M, Buckner JC, Frytak S, Galanis E: Phase II trial of gemcitabine in advanced sarcomas. Cancer 2002; 94:3225-3229.

29 Krown SE, Metroka C, Wernz JC: Kaposi's sarcoma in the acquired immune deficiency syndrome: a proposal for uniform evaluation, response, and staging criteria. AIDS Clinical Trials Group Oncology Committee. J Clin Oncol 1989;7:1201-1207.

30 Eli Lilly and Co: Gemzar ${ }^{\circledR}$ (gemcitabine $\mathrm{HCl}$ ) prescribing information.

31 Burris HA, Moore MJ, Andersen J, Green MR, Rothenberg ML, Modiano MR, Cripps MC, Portenoy RK, Storniolo AM, Tarassoff P, Nelson R, Dorr FA, Stephens CD, Von Hoff DD: Improvements in survival and clinical benefit with gemcitabine as first-line therapy for patients with advanced pancreas cancer a randomized trial. J Clin Oncol 1997; 15: 2403-2413.

>32 Rothenberg ML, Moore MJ, Cripps MC, Andersen JS, Portenoy RK, Burris HA, Green MR, Tarassoff PG, Brown TD, Casper ES Storniolo AM, Von Hoff DD: A phase II trial of gemcitabine in patients with 5-FU-refractory pancreas cancer. Ann Oncol 1996;7: 347-353.

33 Cancer Therapy Evaluation Program: Common Terminology Criteria for Adverse Events, version 3.0. August 2006.
34 Kanavos P: The rising burden of cancer in the developing world. Ann Oncol 2006; 17(suppl 8):viii15-viii23.

35 The London Declaration on Cancer Control in Africa. May, 2007.

36 Lingwood RJ, Boyle P, Milburn A, Ngoma T, Arbuthnott J, McCaffrey R, Kerr SH, Kerr DJ: The challenge of cancer control in Africa. Nat Rev Cancer 2008;8:398-403.

37 UNAIDS/WHO: Epidemiological Fact Sheets on HIV and AIDS (2008 update). Geneva, UNAIDS, 2008.

38 UNAIDS: 2008 Report on the Global AIDS Epidemic. Geneva, UNAIDS, 2008.

$>39$ Bonnet F, Lewden C, May T, Heripret L, Jougla E, Bevilacqua S, Costagliola D, Salmon D, Chêne G, Morlat P: Malignancy-related causes of death in human immunodeficiency virus-infected patients in the era of highly active antiretroviral therapy. Cancer 2004;101:317-324.

40 Therasse P, Arbuck SG, Eisenhauer EA, Wanders J, Kaplan RS, Rubinstein L, Verweij J, Van Glabbeke M, van Oosterom AT, Christian MC, Gwyther SG: New guidelines to evaluate the response to treatment in solid tumors. European Organization for Research and Treatment of Cancer, National Cancer Institute of the United States, National Cancer Institute of Canada. J Natl Cancer Inst 2000;92:205-216. 